\title{
MEMÓRIAS DA CONSTRUÇÃO DE UM EU PROFESSORA
}

\author{
Silvia Adriana Rodrigues \\ Vera Luisa de Sousa \\ Alberto Albuquerque Gomes
}

Resumo

Trazemos nesse texto um recorte do estudo com caráter qualitativo - em desenvolvimento de forma coletiva - que objetiva, com uso de narrativas escritas (cartas) ofertadas por professora(e)s de diferentes níveis de ensino, compreender as características constituintes da identidade e profissionalidade docente ao longo da carreira. Dessa forma, o que ora apresentamos são as reflexões tecidas a partir da narrativa de uma professora do Ensino Fundamental, em início de carreira, que nos levaram ao entendimento de que a escola é espaço privilegiado para a formação das identidades, com contribuições significativas tanto no período de formação quanto no de atuação profissional; bem como de que as singularidades das histórias narradas nos dão elementos sólidos para a compreensão do processo de constituição identitária tanto individual, quanto coletiva.

Palavras-chave: narrativa de professora(e)s; identidade profissional docente; trajetória de formação.

\section{MEMORIES OF BUILDING OF THE TO BE $A$ TEACHER}

\begin{abstract}
We bring in this text a section of the study with a qualitative nature - in development in a collective way that aims, using written narratives (letters) offered by teachers at different levels of education, to understand the constituent characteristics of the identity and teaching professionality throughout the career. Thus, what we present here are the reflections made from the narrative of an elementary school teacher, at the beginning of her career, which led us to the understanding that the school is a privileged space for the formation of identities, with significant contributions in formation and in professional performance; as well as that the singularities of the narrated stories give us solid elements for understanding the process of constituting identity both individually and collectively.
\end{abstract}

Keywords: narrative of teachers; teachers professional identity; formation trajectory.

\section{MEMORIAS DE CONSTRUIR UN SER MAESTRO}

\section{Resumen}

Aportamos en este texto un apartado del estudio con carácter cualitativo - conducido colectivamente - que tiene como objetivo, utilizando narrativas escritas (cartas) ofrecidas por docentes en diferentes niveles de educación, comprender las características constitutivas de la identidad y profesionalidad docente a lo largo de la carrera. Así, lo que aquí presentamos son las reflexiones realizadas a partir de la narrativa de una maestra de primaria, al inicio de su carrera, que nos llevó a entender que la escuela es un espacio privilegiado para la formación de identidades, con aportes significativos en el período de formación y en la carrera profesional; así como que las singularidades de los relatos narrados nos brindan elementos sólidos para comprender el proceso de constitución de la identidad tanto individual como colectivamente.

Palabras clave: narrativa del maestro; identidad profesional del maestro; trayectoria de formacion. 
DOI: $10.12957 /$ teias.2021.54074

PALAVRAS INICIAIS

Talvez os homens não sejamos outra coisa que não um modo particular de contarmos o que somos. E, para isso, para contarmos o que somos, talvez não tenhamos outra possibilidade senão percorrermos de novo as ruinas de nossa biblioteca, para ai tentar recolher as palavras que falem por nós. (LARROSA, 2006, p. 22).

Escrever sobre a escrita de alguém é o desafio atual de nosso grupo de pesquisa, pois, não se trata de criticar ou analisar a forma como alguém escreve, mas de buscar entender como este alguém se descreve, se relata, como compartilha suas vivências e experiências narrativamente. Adicionamos certo grau de complexidade a esta tarefa, já não tão tranquila, pois ela tem sido realizada de forma coletiva e como traz a epígrafe: muitos modos particulares se entrelaçam na tarefa de narrar uma narrativa, no movimento de construir reflexões sobre os ditos e não ditos, tendo em vista que "[...] olhar o olhar do outro é refazer o caminho do pensamento entre o real e a sua representação”. (WEFFORT, 1995, p. 27).

De forma complementar, Weffort (1995, p. 10) assevera que "[...] ver e ouvir demanda implicação, entrega ao outro, estar aberto para vê-lo e/ou ouvi-lo como é, no que diz, partindo de suas hipóteses, de seu pensar". Bem como implica "[...] identificar-me com o outro e ver o mundo através de seu sistema de valores, tal como ele vê; devo colocar-me em seu lugar, e depois, de volta ao meu lugar, contemplar seu horizonte com tudo o que se descobre do lugar que ocupo fora dele [...]" (BAKHTIN, 1997, p. 45). Reafirmamos: uma tarefa de extrema complexidade, que nos tem exigido disciplina, sensibilidade, compreensão e, ao mesmo tempo, capacidade de envolvimento e distanciamento.

Cientes do esforço cognitivo e psicológico que esse caminho metodológico demanda, atenta(o)s aos ensinamentos de Weffort e Bakhtin e empenhada(o)s em superar os desafios que a(s) subjetividade(s) pode $(\mathrm{m})$ impor ao caminho da pesquisa científica que se propõe escutar os sujeitos, enveredamos pelos caminhos dos estudos que trabalham com narrativas e histórias de vida. Salientamos o entendimento da narrativa como gênero discursivo, que funde intersubjetivamente imaginação, história, eventos e experiências pessoais em enredos coerentes, que vão colaborar para o processo de constituição identitária tanto individual, quanto coletivo; consideramos então que subjetividade e coletividade são faces da narrativa. (OLIVEIRA, 2012).

A história de vida tem sido a opção de muitos estudiosos como estratégia que consiste na coleta de dados biográficos de uma ou mais pessoas, sendo que o próprio pesquisador pode ser uma das fontes dessa coleta. Via de regra, as histórias são acessadas por meio de entrevistas semiestruturadas ou outra forma de provocação oral, buscando reconstituir o percurso biográfico do sujeito entrevistado ou episódios deste que a memória acessa.

Moutinho e Conti (2016, p. 1) sinalizam que "[...] falar de nós, de forma narrativa, que fazemos de maneira tão costumaz, possivelmente contribui para que sejam as narrativas a forma discursiva privilegiada para o estudo da construção de sentidos da identidade". No entanto, não escolhemos adotar as narrativas orais para ouvir os docentes, optamos pelo uso de outro instrumento de escuta, por muito tempo relegado ao segundo plano e atualmente retomado com resultados promissores: a carta.

Acreditamos que essa variação metodológica, que se apropria de um instrumento de comunicação já quase em desuso, reflete o momento histórico que vivemos, no qual as Ciências Humanas e Sociais renovam suas perguntas e as estratégias de abordagem de seus fenômenos, buscando formas mais efetivas de retratar a realidade e de apresentar respostas de acordo com as 
exigências contemporâneas.

A opção pela carta também foi motivada pela crença na sua potencialidade de permitir acessar de forma mais espontânea a memória e/ou fragmentos do passado, os vividos carregados de valores afetivos e simbólicos; bem como de transmitir de maneira original o que se pensa, se sente ou se quer dizer ao outro no ato de contar/escrever uma história, as lembranças...

Assim, a metodologia que adotamos em nosso estudo se sustenta na tríade sujeito/pesquisador-carta-sujeito/pesquisado. Talvez o elemento inovador seja o percurso trilhado no qual sujeito pesquisador e sujeito pesquisado são protagonistas, assegurando, conforme recomendam Clandinin e Connelly (2011), a assinatura do pesquisador (essencial) sem subvalorizar as assinaturas dos sujeitos da pesquisa (narradores). Assinala-se aqui um outro desafio, uma vez que neste movimento se entrelaçam subjetividades, pois no exercício de "ouvir" e recontar histórias de outrem tomamos consciência de nós mesmos, vêm à tona emoções e entendimentos desencadeados pela história de outrem, que revelam a historicidade do narrrador/sujeito/pesquisado e do sujeito/leitor/pesquisador e este último, no registro do estudo, se torna também narrador... Por outro lado,

A tensão permanente entre continuidade e transformação do eu, que o processo de narrativização da experiência expõe, faz da narrativa um instrumento privilegiado para a investigação do desenvolvimento humano e, no caso, do desenvolvimento pessoal no contexto profissional dos professores. (OLIVEIRA, 2012, p. 372).

Em linhas gerais, esse caminho pode ser enquadrado na metodologia de estudos qualitativa, na qual o pesquisador escuta, no caso em tela, por meio das cartas, o relato da história de vida de alguém. Momento no qual a relação entre pesquisador(a) e narrador(a) acontece através de um vínculo de confiança mútua construído ao longo de um processo que se inicia quando o segundo, generosamente, compartilha fragmentos de sua vida com o primeiro. A partir daí o diálogo só é possível quando pesquisador(a) e pesquisado(a) estão com os sentidos abertos para essa particular experiência que, para o(a) narrador(a), é revisitar o já vivido com o olhar atualizado do presente e, para o(a) pesquisador(a), significa a aproximação com o igual das vidas ordinárias, mas também com o inusitado das subjetividades que pulsam das palavras, das lembranças, dos sonhos e desejos realizados e a realizar.

A senha para acessar esse universo de possibilidades de conhecermos o processo de elaboração de identidades profissionais foi o envio de cartas a professora(e)s da Educação Básica e do Ensino Superior atuantes em três municípios de duas regiões brasileiras. As missivas contavam um pouco da nossa história como grupo de pesquisa ${ }^{1}$, bem como nosso itinerário de estudos, para em seguida convidar as pessoas a dividirem conosco suas trajetórias de vida, formação e profissionalização. Consideramos nossa estratégia exitosa por duas razões principais: até o momento recebemos 30 cartas como resposta ao chamamento; e, o conteúdo delas tem nos permitido caminhar na direção da concretização do nosso objetivo central que é compreender os caminhos e as características constituintes da identidade e da profissionalidade de docentes a partir de suas versões de si mesma(o)s. Com relação aos conteúdos, se faz necessário destacar também que estes tem nos permitido revistar nossas próprias histórias como profissionais professores, pesquisadores e como pessoa por trás destas identidades.

Importa salientar que compreendemos as identidades como resultado do encontro entre trajetórias socialmente condicionadas e campos socialmente estruturados, configurando-se como

\footnotetext{
1 Trata-se do Grupo de Pesquisa cadastrado no CNPq: Profissão Docente: formação, identidade, representações e saberes - GPDFIRS-FCT/Unesp.
} 
produtos de sucessivas socializaçôes (DUBAR, 2005). Ao tratar especificamente da identidade docente, tomamos esta como "[...] um conjunto de características, experiências e posições de sujeito atribuídas (e autoatribuídas) por diferentes discursos e agentes sociais no exercício de suas funções [...]" (GARCIA, 2010, p. 1, destaque no original). Segundo Zabalza (2004), este processo comporta três dimensões: a pessoal, composta pelas características pessoais do docente como sexo, idade, situação conjugal e motivações; a profissional, que tem como componentes as exigências e necessidades da profissão; e a administrativa, constituída pelas formas de contrato de trabalho, sistema de seleção, características ocupacionais e obrigações de carga horária.

Entendemos então que a identidade docente é dinâmica e tem relação direta com o contexto social e político no qual o professor está inserido. Além disto, ela se constrói a partir dos elementos presentes no universo da docência - o próprio professor, os alunos, os processos cognitivos, as políticas educacionais, o projeto pedagógico, os conhecimentos e habilidades para o exercício da docência. Desta forma, conhecendo os docentes, conhecem-se as mudanças através deles (PIMENTA; ANASTASIOU, 2010).

Assim, de posse das cartas, temos realizado um mergulho analítico-compreensivo buscando identificar, na narrativa, pistas que ajudarão na construção das respostas às questões da pesquisa, uma vez que a carta tem potencial de "[...] representar um mapa de expressão da vida escolar, social e cultural de cada sujeito, que possui a sua história, com memórias suas e da sociedade" (SILVA; SIRGADO; TAVIRA, 2012, p. 273). Buscamos, através das leituras atentas e da escuta sensível, conservar os sentidos e significados dos fatos que foram narrados pela(o)s nossa(o)s interlocutora(e)s.

Diante dessas premissas, cremos que essa modalidade de pesquisa - com histórias de vida é uma forma de elaborar conhecimento a partir da relação entre dois atores: sujeito pesquisador e sujeito pesquisado mediados pela carta.

Nessa direção, o que apresentaremos nos limites desse texto é parte do nosso exercício dialógico ${ }^{2}$ com uma de nossas narrativas, especificamente da Professora Luciana ${ }^{3}$, uma das integrantes do universo de nossas/os narradoras/es, que se dá ante "[...] o reconhecimento de que narrar é atividade simultaneamente social, interpessoal e pessoal”. (OLIVEIRA, 2012, p. 369).

\section{NARRANDO A VOZ DA NARRADORA}

A narrativa colocada em evidência nessa discussão foi oferecida por uma professora das séries iniciais do Ensino Fundamental, em início de carreira (com três anos de experiência na época da escrita da carta, no ano de 2018), que ingressou na docência, quase imediatamente após sua formação inicial no Curso de Pedagogia. Na verdade, a jovem docente apressou a sua colação de grau para poder atender a um convite de trabalho:

[...] fui contratada como PROFESSORA na escola a qual eu havia realizado um trabalho de 12 meses com o PIBID. Porém, agora eu precisaria dar um jeito na minha colação, pois, ainda não estava de posse do meu diploma. Sai da escola e fui direto para a universidade para solicitar a colação de grau na sala do diretor [...] (Excertos da carta de Luciana, 2018, destaque no original).

\footnotetext{
2 Dialógico no sentido bakhtiniano, que remete a uma atitude reflexiva contextualizada, em um processo do qual participam muitas consciências (BAKHTIN, 1997, 2006); neste caso, a dos membros do grupo e da nossa protagonista. ${ }^{3}$ Nome fictício.
} 
DOI: $10.12957 /$ teias.2021.54074

O que nos chama atenção nessa narrativa é o fato de Luciana não ter cogitado formar-se professora. Seu ingresso no curso de Pedagogia foi aleatório, já que seu objetivo era estudar e dar um rumo à própria vida; sua motivação foi não ficar parada. Ela relata que concluiu o Ensino Médio e transitou por outras opções de formação no nível superior, ao final cursando Análise de Marketing como opção para bons empregos. Trabalhou por alguns anos na área de marketing e em 2010, já casada, mudou-se para Corumbá - Mato Grosso do Sul e defrontou-se com a dificuldade de se inserir no mercado de trabalho, tomando a iniciativa de procurar a universidade. Luciana conta que:

Como era o primeiro ano do ENEM, tive que esperar até novembro de 2010 para fazer o mesmo e ingressar na universidade. [...] Chega novembro e fui realizar a prova $[. .$.$] Lembro que o resultado saiu em janeiro e [...] fiquei sem saber$ o que fazer. Assim, como tinha três opções, realizei da seguinte maneira: $1^{\circ}$ opção Direito, $2^{\circ}$ opção Psicologia e $3^{\circ}$ e última opção Pedagogia e quando saiu a nota de corte, verifiquei que não havia conseguido para Direito, pois minha nota era 598 e a do curso de Direito, na primeira chamada, era 785. Eu não fiquei chateada, como já mencionei eu queria mesmo era estudar e dar um rumo em minha vida nessa nova cidade. (Excerto da carta de Luciana, 2018, grifo nosso)

Gomes (1998, p. 121) já argumentou que "[...] a escolha de um curso superior de formação de professores não significa necessariamente uma opção [...]" e nos parece que é o ocorrido com Luciana. O destaque para esta não motivação para o exercício da docência se faz porque tomamos a motivação como um dos elementos que caracteriza a identificação com a profissão e, desta forma, primordial para a constituição da identidade profissional; além de fornecer pistas de uma possível lógica subjacente à identificação, ou não, com os afazeres docentes.

O relato, que se segue na carta, aponta para o início da caminhada de Luciana rumo à elaboração de uma identidade docente. Ela se matricula no curso de Pedagogia e, algum tempo após o início das aulas, nos conta que:

[...] fomos conhecendo os professores, as disciplinas, os autores, [...] e para minha grande surpresa já na terceira chamada do curso de Direito saiu meu nome. E agora? O que eu iria fazer? Trocaria de curso? A resposta veio mais rápido que eu imaginava e NÃOOOOOOOO, eu não troquei de curso e sinceramente foi a melhor decisão que já pude tomar em minha vida (destaque no original).

[...] Quando eu entrei no PIBID, novas descobertas foram feitas em minha vida e a certeza da carreira docente só se confirmava.

[...] E assim foram passando semestre a semestre, descobertas e novas descobertas, medos, anseios, construções e desconstruções e uma vontade de se envolver ainda mais naquele universo e sempre atenta aos conselhos das professoras [...].

Cada professora que eu conhecia melhor mais aumentava o meu desejo de ser como elas. Ah! Esqueci de dizer... Quando escolhi ser professora já sabia que queria ser como aquelas grandes mulheres que agora faziam parte da minha vida. Mulheres reais, com vidas reais, mas com um vasto conhecimento e uma paixão por lecionar e foi naquele exato momento que decidi que queria ser professora universitária (Excertos da carta de Luciana, 2018).

Evidencia-se assim a personificação da Professora almejada por Luciana, a referência que adotará e perseguirá em sua trajetória profissional. Não está dito, por ela, que deseja ser professora da universidade pública; porém, os modelos que destaca, em mais de uma passagem ao longo da carta, são docentes de instituições públicas. Em nenhum momento da narrativa menciona professora(e)s da sua graduação anterior, cursada em escola privada. O espelho para ser refletido 
mostrou-se apenas a partir da experiência no curso de Pedagogia, em uma universidade pública, gratuita e socialmente referenciada na cidade em que passou a viver.

Ainda nessa direção, cabe o destaque para outro trecho no qual nossa narradora sinaliza que não percebe a formação como elemento constitutivo da profissão docente de forma geral, mas como caminho obrigatório que precisa percorrer para atingir o status desejado: Como meu foco é ser professora universitária, não posso esquecer que minha caminhada é longa e que a formação continuada faz parte desse processo [...]" (Excerto da carta de Luciana, 2018), evidenciando, consequentemente, uma concepção utilitarista da profissão, bem como uma percepção equivocada de que somente o(a) professor(a) do Ensino Superior precisaria de um vasto conbecimento e estudar muito. Tal afirmação corrobora o entendimento amplamente circulante do senso comum sobre uma suposta hierarquia no interior da profissão, que seria organizada segundo a idade do público atendido pela professora e pelo professor e o nível de ensino cursado pela(o) estudante.

Há dois elementos a serem mencionados sobre essa idealização do magistério superior. $\mathrm{O}$ primeiro diz respeito ao ingresso nesse nível de ensino que, ao longo de 500 anos de história, foi um privilégio de classe no Brasil; se o foi para estudantes, o que dizer do acesso aos seus púlpitos?

O segundo elemento, que se situa na fronteira do primeiro, é a questão do pertencimento de Luciana a uma classe precarizada do ponto de vista econômico e da negação deste seu lugar social, considerado menor, como sua narrativa nos deixa entrever em situações como a ameaça sofrida, de transferência para estudar em uma escola pública:

[...] estavam implementando o sistema de escolas integrais, que no Rio de Janeiro eram as escolas do Brizola, que eram chamadas de Brizolão, em que as crianças passavam o dia inteiro. E eu tinha pavor de ter que ir estudar nesses centros de estudos, não sei o porquê, mas não eram bem falados no meio dos adolescentes. Então sabendo desse medo, minha irmã fez uma pressão psicológica tão grande que nunca estudei tanta matemática na minha vida inteira, pois, minha irmã determinou que se minhas notas não melhorassem e se eu ficasse reprovada eu iria estudar no Brizolão. (Excerto da carta de Luciana, 2018).

Essa fala explicita o quanto uma história escolar forjada no ambiente da escola privada bastante diverso de um círculo familiar aculturado na periferia de uma grande cidade -, tem a capacidade de construir imagens e registros preconceituosos que podem afetar a percepção sobre a instituição escolar pública e, por que não, sobre a própria realidade doméstica imediata de uma criança em formação, gerando imagens distorcidas de sociedade e de escola pública. Passando, esta última, a ser concebida como lugar perigoso, ruim e, no limite, indesejável para se estar.

Além dessas observações, identificamos o que poderia ser um reforço da nossa impressão de que, para Luciana, o ato de estudar não é um fim em si mesmo; tampouco se relaciona com o processo de formação, parecendo assumir o papel de uma espécie de estratégia para alcançar o objetivo desejado: fugir da escola pública e preparar-se para uma profissão, naquele momento bem distante da docência.

Parte da experiência da nossa narradora com a escola básica está situada no período em que os Centros Integrados de Educação Pública (CIEPs) - projeto educacional de Darcy Ribeiro, implantado por Leonel Brizola quando governou o estado do Rio de Janeiro -, sinalizavam o histórico início do processo de universalização do acesso à escola pública pelas camadas populares, fato que desencadeou profundo incômodo nas classes médias que sentiram seu espaço invadido por pessoas com um histórico social e cultural bastante diverso do seu.

Destacamos que nas últimas décadas houve a implementação de diversas ações afirmativas que favoreceram o acesso e a permanência de sujeitos das classes populares às instituições de educação básica. Mas, o fenômeno da expansão de vagas e oportunidades na escola pública possui 
DOI: $10.12957 /$ teias.2021.54074

uma outra faceta, qual seja, a migração da(o)s filha(o)s classe média para o sistema privado de ensino. Nesta direção, Nogueira (2010, p. 216) assinala que

[...] o atual cenário educacional nacional [sinaliza], no curto prazo, um aumento da demanda pelo ensino privado que já escolariza boa parte das camadas médias, as quais, há décadas, abandonaram o setor público em função da queda na qualidade de seu serviço e da deterioração do clima social ali reinante. $\mathrm{O}$ que constitui apenas o aprofundamento de uma tendência que já vem sendo observada desde os anos 1990. E mantidas as condições econômicas atuais, essa tendência não deverá ser revertida, no curto prazo, nem mesmo sob o impacto (ainda não mensurado) das esparsas políticas de ação afirmativa que oferecem vantagens aos egressos da rede pública, por exemplo, no vestibular. Ao que tudo indica, transferir seus filhos para a rede pública seria um risco que os pais das classes médias, de um modo geral, não aceitariam correr, no presente contexto.

As reflexões de Nogueira (2010) nos levam a reafirmar que nas entrelinhas da carta de Luciana há uma forte rejeição às escolas do sistema público de ensino. Esse estranhamento frente ao outro, que a experiência familiar de Luciana parece ter alimentado e que expõe a fragilidade socioeconômica de sua própria classe, passa a compor seu repertório de preconceitos contra a escola pública como lugar de formação.

Meu ingresso na escola comesa um pouco tardio, aos sete anos de idade em uma escola particular intitulada Escola Cenecista São Simão, pois, minha irmã que também é professora assim como fez com meu irmão nos alfabetizou em casa e só ao completar os sete anos que nos matriculou em uma escola regular e também trabalhava nessa mesma escola e ganhou bolsas de estudos para os irmãos. (Excerto da carta de Luciana, 2018, grifo nosso).

No excerto anterior chama a atenção a ponderação de Luciana sobre uma entrada tardia na escola - aos sete anos - que na verdade, na época, era a idade de ingresso no Ensino Fundamental; quer dizer, não houve atraso. Neste momento histórico a Educação Infantil - pré-escola - ainda não era parte da educação básica, logo, seu oferecimento era restrito às instituições particulares fora do alcance de nossa protagonista. Mas, sua primeira experiência com a escola foi relatada como positiva, em grande medida pelo lugar de destaque que ocupou de imediato.

E me lembro como se fosse hoje meu primeiro dia ao ambiente escolar que foi marcado com muitas emoções e descobertas. A gentil e delicada professora Kátia fez as apresentações e pediu para que eu falasse meu nome, minha idade e o que eu mais gostava de fazer e como a mesma identificou que eu já sabia ler, me deu atividades diferenciadas [...]

Já na segunda semana de aula eu fui avançada para uma classe em que as crianças já sabiam ler e escrever. Desta forma, fui avançando e descobrindo coisas novas e sempre ficava fascinada com as aulas fora do ambiente escolar. (Excertos da carta de Luciana, 2018).

Sua irmã mais velha - professora e responsável pela alfabetização dos irmãos menores e por seu ingresso na rede privada de ensino por meio de bolsas de estudo -, decidiu mudá-la de escola ao término do Ensino Fundamental para evitar que cursasse o Normal ou o Técnico em Contabilidade, que em sua avaliação não ofereciam a formação profissional desejada para a irmã mais nova. Então, naquilo que nomeia gesto de rebeldia, Luciana pede à mãe para matriculá-la na modalidade Educação de Jovens e Adultos, no que é atendida revelando ausência de 
preocupação materna com a qualidade do processo de escolarização formal da filha e, também, o, muito provável, baixo capital cultural da família.

Após concluir o Ensino Médio na modalidade Educação de Jovens e Adultos - EJA, Luciana prestou vestibular para uma instituição privada, mas, sem condições de pagar as mensalidades, desiste da matrícula e ingressa no mercado de trabalho conforme já destacado em trecho da carta trazido anteriormente. Três anos depois ingressa e se forma em Analista de Marketing, também numa instituição privada, concluindo a etapa superior de sua formação. A instituição pública de ensino só se mostrou como possibilidade à Luciana ao se mudar do Rio de Janeiro para uma cidade do interior do estado de Mato Grosso do Sul. A proximidade de sua residência com um campus de uma universidade pública foi o elemento que a conectou a um cenário que até aquele momento não compunha sua realidade; já que a escola privada foi o espaço, desde sempre, de sua experiência educativa.

É necessária uma investigação sociológica para comprovar a hipótese que aqui aventamos, mas muito possivelmente brasileiras/os que frequentaram a escola a partir do final dos anos de 1980, viveram o mesmo tipo de experiência com a escola pública básica. Ou seja, não a conheceram, senão por ouvirem falar de suas mazelas e fragilidades, ajudando a consolidar a imagem desta escola como um local onde os nossos filhos (das camadas médias) não poderiam estar. Nesta direção, cabe o apontamento de Dias Sobrinho (1979, p. 16) - que nos parece atual e oportuno - de que:

[...] a nenhuma outra classe social a escola exerce tanto fascínio quanto às médias. Efetivamente, são estas as que mais dependem da educação, tanto pelos seus projetos ascensionais e pelo reconhecimento social, quanto por exigências da estrutura ocupacional e desejo de participação nas esferas de poder ou de delas não serem excluídas.

Dessa maneira, a educação passou a ser considerada o principal mecanismo de ascensão social. Embora o autor refira-se à educação em geral, podemos expandir esse raciocínio para a universidade que é pressionada a abrir suas portas para um novo segmento social (GOMES, 1998). Este mesmo autor, destacou a preferência das classes médias pela escola particular básica e pela escola pública de Ensino Superior, revelado pelo aumento do

[...] controle das universidades pelo Estado [...] na medida em que este investe também em sua estrutura física. [...] A Universidade passa a ser encarada como ponto de uma busca incessante de conhecimento [...]. Inicialmente, as universidades voltam-se para a formação dos filhos da burguesia; porém, logo surgiram as pressões para que estas se abrissem para os filhos da classe média que almejavam mecanismos de ascensão social. (GOMES, 1998, p. 16).

Corroborando as afirmações anteriores, Nogueira (2010, p. 220) aponta que o investimento em educação aumentou em todas as classes, mas as médias, em particular, intensificaram as estratégias para se apropriar de diferentes recursos - culturais e escolares - em prol de uma formação que permita seus filhos subirem na escala social.

Como vimos em excerto já destacado da carta, Luciana marcou como opções de curso no Sistema de Seleção Unificada (SISU), pela ordem, Direito, Psicologia e Pedagogia; e, também aqui é razoável imaginar que suas opções traduzam as dificuldades para lidar com o pertencimento de classe e o desejo de ascender à outra, superior na pirâmide social. Mas, entendemos que também indicam que, apesar de uma trajetória na rede privada, a formação de nossa Professora não contou com um investimento intencional para isso. Esta narrativa demonstra que ao contar sua história Luciana vai, por meio daquilo que poderíamos chamar de interpretação do vivido, atribuindo 
DOI: $10.12957 /$ teias.2021.54074

sentido à sua caminhada para a docência. Ou seja, embora tivesse o curso de Direito como primeira opção, ao ver seu nome "[...] na terceira chamada do curso [...]", declinou, pois já estava matriculada e cursando a Pedagogia; em suas palavras: "[...] eu não troquei de curso (Pedagogia) e sinceramente foi a melhor decisão que já pude tomar em minha vida [...]" (Excertos da carta de Luciana, 2018).

Após a conclusão do curso, Luciana ingressa na docência e enfrenta os mesmos desafios de outra(o)s tanta(o)s profissionais...

Preparei o planejamento para aquele primeiro dia e como atividade inicial para conhecer os alunos, levei a caixa de sensações que aprendemos fazer nas aulas de materiais pedagógicos e assim me aproximei de algumas crianças, pois, como a própria coordenadora havia mencionado na entrevista, aquela era um turma complicada[...]. Os dias foram passando e cada dia acontecia algo novo: Um dia os alunos brigavam, no outro choravam e no outro queriam me agredir, aliás, cheguei a receber uma cadeirada de um deles... E ouvia os comentários: "Essa daí não chega ao meio do ano..."; "Hummm, professora novinha nessa turma, tadinha dela". Porém, as coisas foram se ajeitando [...] Quando chegou o mês de julho e íamos entrar de férias, fui agradecer a equipe pedagógica pela oportunidade de trabalho e como olhar de espanto a coordenadora me perguntara: O que houve? Não vai mais ficar? E eu sorrindo apenas respondi: Adoraria. E assim estou nessa escola desde fevereiro de 2015 até a presente data. (Excerto da carta de Luciana, 2018).

Sobre os primeiros movimentos no exercício da docência, Tardif e Lessard (2005) sinalizam que, ao mesmo tempo em que as experiências docentes são particulares, elas também são coletivas tendo em vista que os desafios e condições de trabalho não são vividos de forma isolada;

[...] as vivências mais íntimas excedem a intimidade do Eu psicológico, para inscreverem-se numa cultura profissional partilhada por um grupo, graças à qual seus membros atribuem sensivelmente significados análogos a situações comuns. Neste sentido, viver uma situação profissional como um revés ou um sucesso não é apenas uma experiência pessoal. Trata-se também de uma experiência social [...]. Em síntese, o que nos interessa com essa noção de experiência social do ator é precisamente as situações e significações pelas quais a experiência de cada um é também, de certa maneira, a experiência de todos. (TARDIF; LESSARD, 2005, p. 53).

Poderíamos comparar os primeiros movimentos no exercício da docência aos movimentos da vida de Luciana, pois as experiências construídas ao longo da existência seriam impossibilitadas fora do círculo que envolve as dimensões pessoal e coletiva. Afinal somos e existimos como indivíduos e como coletividade e, assim, acumulamos nossas bagagens culturais, sociais, profissionais, e todas as demais, que vão sendo organizadas a partir do entrecruzamento do resultado que essas vivências deixam em nós ou, à maneira larrosiana, do modo como nos afetam.

Reforçamos aqui a percepção de que as narrativas revelam de forma clara que: "[...] o modo de organização coletiva de um grupo em um dado momento histórico; reflete, nos planos social e pessoal, motivações e intencionalidades particulares [...]" (OLIVEIRA, 2012, p. 370), ao passo que também nos permitem a "[...] compreensão dos marcadores que vão delineando e sustentando a trajetória profissional, que, por vezes, atravessa profundas contradições acerca das possibilidades de se tornar profissional” (SILVA; SIRGADO; TAVIRA, 2012, p. 265).

Luciana, ao longo de sua carta, vai confirmando essas ponderações quando, de certo modo, nega seu pertencimento de classe ao adotar o orgulho como sentimento central na sua trajetória de escolarização na rede privada que, contudo, será transposto para a escola pública no momento em 
DOI: $10.12957 /$ teias.2021.54074

que experiencia a graduação em Pedagogia numa universidade federal. É a Estudante Luciana, forjada na rede privada, a caminho da Professora Luciana, formada pela universidade pública que, por sua tradição de ser socialmente referenciada pelas demandas da coletividade, apresenta à nossa Protagonista a novidade de pertencer às camadas populares, originalmente, por ela, refutadas como lugar de pertença.

Comparando a fala abaixo com trechos anteriormente citados da narrativa, é possível notar que Luciana aqui traduz o que estamos a afirmar:

Como meu foco é ser professora universitária, não posso esquecer que minha caminhada é longa e que a formação continuada faz parte desse processo e desta maneira fiz meu primeiro processo seletivo para a turma de Mestrado em Educação da UFMS e infelizmente não consegui [...] fui procurar no portal da educação um curso de especialização a distância e quando já havia realizado a inscrição recebo um e-mail de uma queridíssima professora me [chamando para] inscrição na especialização da UFMS [...] Lembro que na época cheguei na escola toda entusiasmada avisando as colegas a respeito da especialização e ouvi coisas tipo: 'Não farei qualquer coisa, só por fazer...' 'Estudar pobreza e desigualdade social? Para que? 'Isso não tem nada relacionado com minha área...' E fiquei confusa diante de tantas coisas que ouvi, como por exemplo: Se não existe relação com a desigualdade social e a pobreza com a realidade das escolas? Se essa área era fazer 'qualquer coisa'. Enfim, ignorei os comentários e estava ansiosa para o primeiro encontro [...] e a cada módulo novo dessa especialização eu desconstruía muitos conceitos, inclusive a respeito do Bolsa Família, [que passei] 14 meses estudando [...] foi [este] justamente o tema do meu trabalho de conclusão. (Excerto da carta de Luciana, 2018).

O recorte destacado revela a frustração de Luciana diante da reprovação no processo seletivo para a pós-graduação stricto sensu. Sentimento superado ao longo da continuidade de um processo de formação que se desenrola e a convoca, por meio das contradições postas por seu grupo de colegas, a refletir sobre seu lugar de classe e, especialmente, sobre as relações sociais de produção e o papel da escola nessa composição, corroborando o apontamento de Sousa et al. (2019, p. 168-169, grifo no original) de que “[...] a escola, quase uma espécie de 'bioma', gesta, produz e reproduz características da profissionalidade do(a) profissional que a integra, concebendo-se como um lugar de elaboração de identidades profissionais [...]".

Olhando para a trajetória de nossa narradora vislumbramos uma experiência social e educativa marcada pelo preconceito "ontra e pelo distanciamento dos espaços ocupados pelas camadas populares e seu local de escolarização: a escola pública. Perspectiva que vai, no movimento da sua existência e das experiências que realiza no âmbito da formação, apontando na direção da confirmação do bioma escolar como portador do embrião da identidade docente. Neste ponto, salientamos que este é um dado que vem se tornando recorrente em nosso estudo, emergindo de forma significativa em quase todas as cartas-narrativas analisadas pelo grupo até o momento.

\section{PALAVRAS FINAIS}

E, talvez nessa história em que um homem se narra a si mesmo, nessa história que talvez não seja senão a repetição de outras histórias, possamos adivinhar algo daquilo que somos. (LARROSA, 2006, p. 21).

Trabalhar com narrativas de histórias de vida supõe acessar a memória das pessoas, o que 
nos coloca diante do desafio de contarmos apenas com as informações que nos chegam a partir da percepção do próprio narrador em quem temos que confiar para podermos compreender as questões que alimentam nossa pesquisa. Clandinin e Connelly (2015, p. 77) nos ajudam a lidar com esta questão, pois segundo os autores:

Uma das tensões mais fortes e sempre presente é o como compreendemos o lugar das pessoas na pesquisa. Um dos modos mais simples de dizer isto é que na pesquisa formalista, pessoas, se chegarem a ser identificadas, são consideradas exemplares de uma forma - de uma ideia, uma teoria, uma categoria social. $\mathrm{Na}$ pesquisa narrativa, as pessoas são vistas como a corporificação de histórias vividas. Mesmo quando os pesquisadores narrativos estudam narrativas institucionais, como as histórias da escola, as pessoas são encaradas como vidas compostas que constituem $e$ são constituídas por narrativas sociais e culturais (grifos nossos).

Tal consideração é bastante apropriada como guia para a análise das cartas de professoras/es que compõem o espectro de nossa investigação, uma vez que o estudo tem nos permitido ter contato com singularidades, vivências e experiências $\mathrm{da}(\mathrm{o}) \mathrm{s}$ professora(e)s que nos contaram suas histórias; mas atende, particularmente, ao caso da narrativa de Luciana, cujo discurso, ao longo da escrita, explicita uma visão estereotipada da escola pública e da carreira docente que carrega um preconceito de classe. Também sobre esta consideração, Moutinho e Conti (2016, p. 2) salientam que "[...] a narrativa pessoal é o resultado de um recurso aos discursos ou narrativas sociais dominantes e também, o processo no qual essas mesmas narrativas sociais são progressivamente reconstruídas no plano das relações sociais".

Luciana compartilha uma visão de mundo que, supomos, poderia ser diferente se suas primeiras experiências com a escola não tivessem contado com bolsas de estudos, caso em que teria vivido suas experiências num ambiente com viés cultural e econômico mais próximo ao de sua família. Fato que, em nossa opinião, teria grandes chances de modificar a percepção negativa da escola pública explicitada no início de sua narrativa. O discurso negando, de certa forma, a validade desta e reforçando a superioridade da escola privada foi incorporado por Luciana, possivelmente, por sua experiência numa instituição escolar privada onde circulam com maior potência as narrativas sociais dominantes.

Pensando na afirmativa anterior, por mais angustiante (quiçá frustrante) que seja, temos que admitir que algumas ideias - que consideramos equivocadas - expostas por Luciana, em sua carta, traduzem o pensamento de uma parcela significativa da população, especialmente nos tempos atuais, nos quais isto se torna inegável, impossível de não admitir...

Assim, a contradição que irrompe da carta de nossa narradora apresenta, de um lado, a escola pública como local inadequado para se estar e se formar e, de outro, o desejo, por ela alimentado, de ocupar um 'posto' percebido como capaz de conferir status social a quem o ocupa: o de professora universitária... "[...] terminando a especialização, agora deixo de ser graduada para ser especialista e fico um pouco mais perto do men grande objetivo: Ser professora universitária”. (Excerto da carta de Luciana, 2018, grifo nosso). Cremos que seja relevante destacar aqui que a inserção profissional de Luciana na escola básica funciona como um processo ascensional na carreira docente, ou seja, o nível que ocupa é o primeiro degrau rumo ao seu grande objetivo.

Há, pois, dois grandes desafios impostos a nós, professore(a)s e formadore(a)s de professore(a)s. O primeiro é buscar meios para desconstruir, em nossos espaços de atuação, concepções distorcidas sobre educação, escola pública e sobre ser professor(a), tendo em mente que "[...] a formação docente deve comprometer-se coma tomada de consciência e o posicionamento reflexivo e crítico em relação aos próprios modos cotidianos de ação [...]" (OLIVEIRA, 2012, p. 373). 
O segundo desafio, estreitamente relacionado ao primeiro, diz respeito ao necessário fortalecimento das bases para construções identitárias de sujeito social e profissional mais humanizadoras - no sentido freireano - capazes de fomentar uma educação problematizadora, essencialmente reflexiva e dialógica num "[...] esforço de propor aos indivíduos dimensões significativas de sua realidade, cuja análise crítica lhes possibilite reconhecer a interação de suas partes”. (FREIRE, 1981, p. 113).

Compreendemos a escola como espaço/momento de construção e reconstrução de conhecimentos, mas também como lugar em construção, uma vez que sua dinâmica exige de seus atores - em especial da(o)s professora(e)s, a todo momento, esforços para provocar e encarar mudanças sociais recorrentes e necessárias.

Finalizamos esse texto com certa angústia, pois como nos ensinou Weffort (1995, p. 39): "[...] escrever dá muito trabalho porque organiza e articula o pensamento na busca de conhecer o outro, a si, o mundo". Um mundo que tem nos mostrado uma face sombria com a qual não concordamos e que nos provoca, ainda que momentaneamente, o sentimento de incapacidade de promover mudanças significativas no curto prazo. Por outro lado, alimentamos a esperança de dias melhores e tentamos manter sempre vivo o ensinamento freireano sobre o sonho... Diz ele:

Sonhar não é apenas um ato político necessário, mas também uma conotação da forma histórico-social de estar sendo de homens e mulheres. Faz parte da natureza humana que, dentro da história, se acha em permanente processo de tornar-se. Fazendo e refazendo-se no processo de fazer história [...] Não há mudança sem sonho como não há sonho sem esperança [...] (FREIRE, 1992, p. 91).

Sonhar, portanto, não deve ser considerado um exercício impróprio ao espaço escolar: ou seja, por mais formalizado e burocratizado que ele esteja, pode - e precisa - ser o lócus onde as pessoas aproximam-se de seus sonhos e objetivos, desenvolvendo suas capacidades e habilidades, quer seja na condição de estudante ou na de professor ${ }^{4}$.

\section{REFERÊNCIAS}

BAKHTIN, Mikhail. Estética da criação verbal. 2. ed. São Paulo: Martins Fontes, 1997.

BAKHTIN, Mikhail. Marxismo e filosofia da linguagem. 12. ed. São Paulo: Hucitec, 2006.

CLANDININ, D. Jean; CONNELY, F. Michael. Pesquisa narrativa: experiência e história em pesquisa qualitativa. 2. ed. Tradução do Grupo de Pesquisa Narrativa em Educação de Professores. Uberlândia: EDUFU, 2015.

DIAS SOBRINHO, José. Universidade e classes médias: aspectos do caso brasileiro. Educação e Sociedade, São Paulo, n. 4, p. 111-121, set. 1979.

DUBAR, Claude. A socialização: construção das identidades sociais e profissionais. Tradução de Andréa Stahel M. da Silva. São Paulo: Martins Fontes, 2005.

FREIRE, Paulo. Pedagogia do Oprimido. 10. ed. Rio de Janeiro: Paz e Terra, 1981.

FREIRE, Paulo. Pedagogia da Esperança: reencontro com a Pedagogia do Oprimido. Rio de Janeiro: Paz e Terra, 1992.

GARCIA, Maria Manoela. Identidade docente. In: OLIVEIRA, Dalila Andrade; DUARTE, Adriana Maria Cancela; VIEIRA, Lívia Maria Fraga. Dicionário: trabalho, profissão e condição

\footnotetext{
${ }^{4} \mathrm{O}$ presente trabalho foi realizado com apoio da Universidade Federal do Mato Grosso do Sul e da Coordenação de Aperfeiçoamento de Pessoal de Nível Superior - Brasil (CAPES) - Código de Financiamento 001.
} 
DOI: $10.12957 /$ teias.2021.54074

docente. Belo Horizonte: UFMG/Faculdade de Educação, 2010. CDROM. Disponível em http://www.gestrado.org/?pg=dicionarioverbetes\&id=46. Acesso em 08 de mai. 2015.

GOMES, Alberto Albuquerque. Evasão e evadidos: o discurso dos ex-alunos sobre evasão escolar nos cursos de licenciatura. 1998.175f. Tese (Doutorado em Educação) - Faculdade de Filosofia e Ciências - UNESP, Marília, 1998.

LARROSA, Jorge. Pedagogia profana: danças piruetas e mascaradas. 4. ed. Belo Horizonte: Autêntica, 2006.

MOUTINHO, Karina; CONTI, Luciane de. Análise narrativa, construção de sentidos e identidade. Psicologia: Teoria e Pesquisa, v. 32 n. 2, p. 1-8, abr.-jun. 2016.

NOGUEIRA, Maria Alice. Classes médias e escola: novas perspectivas de análise. Currículo sem Fronteiras, v. 10, n. 1, p.213-231, jan./jun. 2010.

OLIVEIRA, Maria Claudia Santos Lopes. Narrativas e desenvolvimento da identidade profissional de professores. Caderno Cedes, Campinas, v. 32, n. 88, p. 369-378, set.-dez. 2012. PIMENTA, Selma Garrido; ANASTASIOU, Lea das Graças Camargos. Docência no Ensino Superior. 4. ed. São Paulo: Cortez, 2010.

SILVA, Daniele Nunes Henrique.; SIRGADO, Angel Pino; TAVIRA, Larissa Vasques. Memória, narrativa e identidade profissional: analisando memoriais docentes. Caderno Cedes, Campinas, v. 32, n. 88, p. 263-283, set./dez., 2012.

SOUSA, Vera Luisa et al. Professora alfabetizadora: uma narrativa interrompida. In: Seminário Nacional De Pesquisas E Práticas Na Educação Da Infância, IV, 2019. Anais..., Três Lagoas: UFMS-CPTL, 2019. p. 161-171. Disponível em https://sppeiufmscptl.wixsite.com/pedagogia/anais. Acesso em 07 out. 2019.

TARDIF, Maurice; LESSARD, Claude. O trabalho docente: elementos para uma teoria da docência como profissão e interações humanas. Petrópolis: Vozes, 2005.

WEFFORT, Madalena Freire. Observação, registro, reflexão. Espaço pedagógico: São Paulo, 1995. ZABALZA, Miguel Angel. O ensino universitário seu cenário e seus protagonistas. Porto Alegre: Artmed, 2004.

\section{Informações do(a)(s) autor(a)(es)}

Sílvia Adriana Rodrigues

Universidade Federal do Mato Grosso do Sul (UFMS) - Campus de Três Lagoas

E-mail: silvia.rodrigues@ufms.br

ORCID: http://orcid.org/0000-0003-1249-3976

Link Lattes: http://lattes.cnpq.br/4514642359270091

Vera Luísa de Sousa

Universidade Federal do Mato Grosso do Sul (UFMS) - Campus de Três Lagoas

E-mail:vera.luisa@ufms.br

ORCID: https://orcid.org/0000-0003-2802-7996

Link Lattes: http://lattes.cnpq.br/5286045311488287

Alberto Albuquerque Gomes 
Universidade Estadual Paulista (UNESP) - Campus de Presidente Prudente E-mail: alberto.gomes@unesp.br.

ORCID: https://orcid.org/0000-0002-2260-322X

Link Lattes: http://lattes.cnpq.br/2624279208302164 